\title{
Mudanças climáticas nos ecossistemas agrícolas e naturais: medidas de mitigação e adaptação
}

\author{
Leticia de A. Dias'1, João Batista Tolentino Júnior² e Leosane Cristina Bosco²
}

\begin{abstract}
Resumo - O objetivo deste trabalho foi apresentar uma revisão bibliográfica sobre os principais impactos que os ecossistemas agrícolas e naturais vêm sofrendo com a ocorrência das mudanças climáticas, e então expor algumas estratégias de mitigação dos impactos e da adaptação destes ecossistemas às mudanças. Dentre as estratégias, podem-se citar o uso de modelos de simulação de culturas como suporte ao conhecimento e tomadas de decisão, o uso de genes de plantas adaptadas às alterações climáticas no melhoramento genético, e o uso de políticas públicas voltadas ao desenvolvimento sustentável.
\end{abstract}

Termos para Indexação: Aquecimento Global; Vulnerabilidade de Ecossistemas; Conservação.

\section{Climate change in natural and agricultural ecosystems: mitigation and adaptation strategies}

Abstract - The objective of this work was to present a bibliographic review about the main impacts that the agricultural and natural ecosystems have been suffering with the occurrence of climate changes, and then to expose some strategies to mitigate the impacts and the adaptation of these ecosystems to the changes. Among the strategies addressed, we can mention the use of crop simulation models to support knowledge and decision making, the use of plant genes adapted to climate change in genetic improvement, and the use of public policies aimed at sustainable development.

Index Terms: Global Warming; Ecosystem Vulnerability; Conservation.

\section{Introdução}

Os ecossistemas agrícolas e os naturais estão diretamente relacionados, ou seja, qualquer impacto sofrido por um gera consequências sobre o outro. Independentemente do nível de responsabilidade que a atividade antrópica tem sobre a intensificação das mudanças climáticas, a temática deve ser abordada e transmitida para todos os setores da comunidade, e não permanecer apenas no meio científico. A partir da difusão do assunto torna-se possível tomar atitudes que garantam a boa condição de vida nos ecossistemas e a qualidade da produção agrícola, diminuindo os efeitos das mudanças climáticas.

O efeito das mudanças climáticas é mais percebido em algumas regiões do que em outras, e a forma como as pessoas interpretam estes efeitos - como as alterações no regime anual de chuvas e nas temperaturas máximas e míni- mas, por exemplo - depende do seu nível de informação a respeito do assunto (ROSENZWEIG et al., 2014). A partir do momento em que se percebem as consequências das mudanças climáticas, observa-se uma busca popular por formas de restringir as consequências das ações antrópicas sobre os ecossistemas naturais, já que muitas destas ações intensificam os efeitos das mudanças climáticas (PECL et al., 2017).

Reduzir os impactos causados pelo fenômeno climático sobre as atividades econômicas também deve ser um foco de ação (FOGUESATTO et al., 2019). Esta é a realidade que se apresenta no setor agrícola, com estratégias que podem envolver o uso de variedades de cultivo mais resistentes, e de modelos de simulação de culturas que permitem identificar a época ideal para o plantio e o uso de agrotóxicos.

Tendo em vista o exposto, este trabalho apresenta-se como uma revisão bibliográfica a respeito dos principais impactos que os ecossistemas agrícolas e naturais vêm sofrendo em decorrência das mudanças climáticas. Aliado a isso, buscou-se abordar algumas estratégias de mitigação dos impactos e da adaptação destes ecossistemas a estas mudanças.

\section{A problemática das mudanças climáticas}

Barry (2013) afirma que nos últimos milhares de anos o clima passou por variações que afetaram a agricultura e os ecossistemas naturais. A inconstância do clima pode ser evidenciada a partir de mudanças diretas nos anéis de crescimento das árvores, nos registros em testemunhos de gelo e em sedimentos do oceano, que fornecem registros que podem ser referentes a um período anual, e até mil anos. Tais registros podem indicar a ocorrência de mudanças

Recebido em 8/8/2019. Aceito para publicação em 1/4/2020,

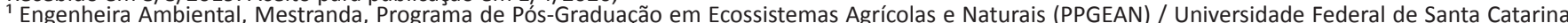
(UFSC), Centro de Ciências Rurais, Campus de Curitibanos, Curitibanos, SC, Brasil. CEP: 89.520-000. E-mail: leticia diaas@yahoo.com.br.

Engenheiro-agrônomo (Docente), Dr., PPGEAN / UFSC, Centro de Ciências Rurais, Campus de Curitibanos. E-maii: joao.tolentino@ufsc.br. / leoane.bosco@ ufsc.br. 
climáticas ou de variações climáticas. Mudanças climáticas podem ser observadas a partir de mudanças locais ou globais, estatisticamente significativas, nas características climáticas de longo prazo. Elas podem ser decorrentes de ação antrópica ou de processos naturais. As variações climáticas, diferentes das mudanças climáticas, são cíclicas e ocorrem em um curto período, sendo processos internos comuns do sistema climático.

As principais formas de identificar a ocorrência de mudanças climáticas em dados históricos são através de alterações nas médias de temperatura do ar e da pluviosidade, que interferem diretamente na circulação atmosférica do globo (BARRY, 2013). O aumento do nível do mar, que representa um risco para as áreas costeiras, e o aumento da ocorrência de eventos extremos como secas, inundações, tempestades e da intensificação do fenômeno de El Niño, também podem ser relacionados às mudanças climáticas, devido ao aumento das temperaturas (CAl et al., 2014).

Uma das causas das mudanças climáticas é a intensificação do efeito estufa e o consequente aquecimento global. O homem contribui para o aquecimento global através da liberação de gases como $0 \mathrm{O}_{3}, \mathrm{CO}_{2}, \mathrm{CH}_{4}, \mathrm{NO}_{x}$ e os CFCs, que acumulam na atmosfera e reagem com seus componentes naturais (IPCC, 2018). O novo relatório do Painel Intergovernamental sobre Mudanças Climáticas - IPCC (2018) traz as ações necessárias para cumprir com a decisão tomada durante a Convenção-Quadro das Nações Unidas sobre Mudanças Climáticas de reduzir as emissões atmosféricas e, consequentemente, o aumento previsto da temperatura média do planeta de $2^{\circ} \mathrm{C}$ acima dos níveis préindustriais para $1,5^{\circ} \mathrm{C}$ até o ano de 2100 . A Figura 1 ilustra o comportamento da temperatura média do globo, de acordo com as modificações nas emissões antropogênicas. Apesar de o provável aumento de $1,5^{\circ} \mathrm{C}$ trazer consequências menos severas do que as projeções para $2^{\circ} \mathrm{C}$ (IPCC, 2018), ainda existem consequências sobre a saúde dos ecossistemas, podendo causar a extinção de espécies e mudanças nas características de biomas (SCARANO, 2017).

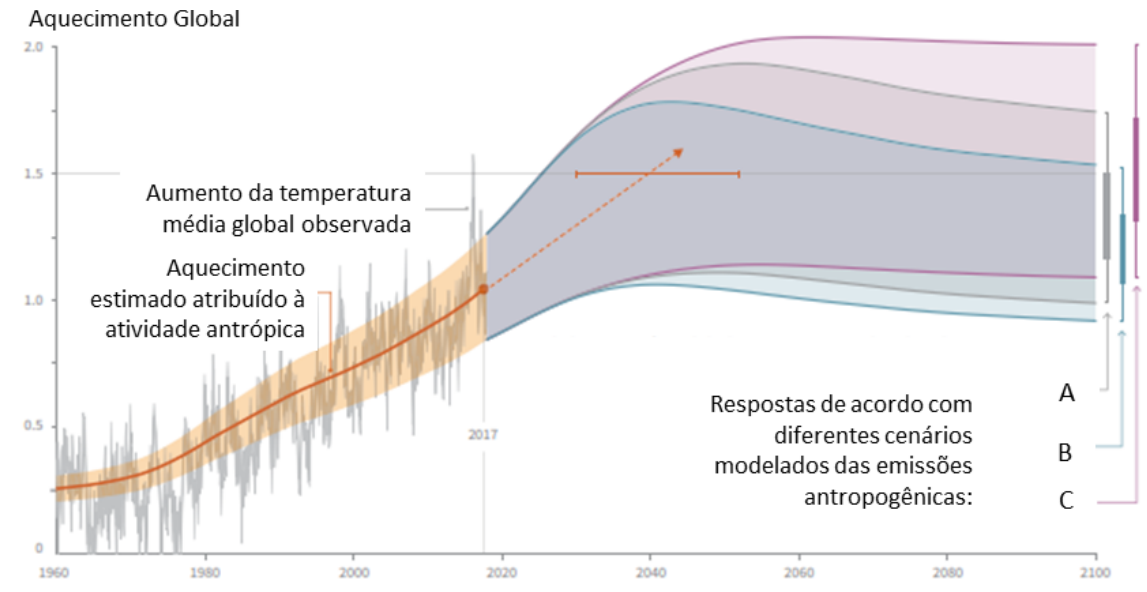

Figura 1. Aumentos da temperatura média global observada e modelagem de repostas às emissões antrópicas de CO2 e radioatividade. Autor: Adaptado de IPCC (2018)

Figure 1. Observed global average temperature increase, and future increase due to different anthropic emissions. Author: Adapted from IPCC9 2018)

A - Modelagem atual de emissões: As emissões globais de CO2 atingem 0 em 2055 enquanto as forças radioativas são reduzidas após 2030. O aumento médio chega próximo a $2^{\circ} \mathrm{C}$.

$\mathrm{B}$ - Reduções mais rápidas das emissões de $\mathrm{CO} 2$ implicam uma probabilidade mais alta de reduzir o aumento da temperatura média para $1,5^{\circ} \mathrm{C}$ até 2100 .

C - Nenhuma redução imediata nas emissões de partículas radioativas resulta em uma menor probabilidade de reduzir o aumento da temperatura média para $1,5^{\circ} \mathrm{C}$ até 2100 .

Algumas consequências globais já observadas são o aquecimento e o derretimento de geleiras, com o aumento no nível dos oceanos. Outros eventos extremos, como tempestades de vento e as ondas de calor também têm sido mais frequentes (IPCC, 2013). Dubreuil et al. (2019), utilizando a classificação de Köppen para evidenciar as mudanças climáticas no Brasil, atestam o crescimento das regiões áridas no Nordeste brasileiro, a mudança do clima temperado para tropical em diversas regiões do Sul, e a redução da frequência de anos hiperúmidos na Amazônia. O Brasil contribui para este cenário com o desmatamento na Amazônia para plantação de lavouras e criação de gado, e com a produção de arroz alagado (EMBRAPA, 2008). Os setores de geração de energia e processos industriais também adicionam forças às contribuições brasileiras (ICLEI, 2015). Apesar disso, a agricultura também sofre os impactos destas mudanças climáticas devido ao aquecimento atmosférico, que pode representar ameaças ao cultivo de uma série de culturas, com o risco de mudanças na geografia da produção agrícola atual do Brasil (GHINI et al., 2011).

As culturas de grãos como café e soja serão as mais afetadas, devido a sua sensibilidade às altas temperaturas e ao estresse hídrico, o que pode representar impactos para a economia do país (TAVARES et al., 2018). A cana-deaçúcar e o milho poderão ter sua área de cultivo expandida, por serem plantas do tipo $\mathrm{C} 4$ e responderem positivamente a uma maior quantidade de $\mathrm{CO}_{2}$ na atmosfera (EMBRAPA, 2008, DAMATTA et al., 2019). Assim, Martins et al. (2010) e DaMatta et al. (2019) chamam atenção para a importância do estudo e da aplicação de estratégias de mitigação dos efeitos e a necessidade de adaptação do setor agrícola às mudanças climáticas que vêm ocorrendo.

Ainda sobre o impacto na agricultura, Rosenzweig et al. (2014) afirmam que avaliar e comparar o nível de interferência que diferentes regiões agrícolas sofrem é uma tarefa difícil. Ao testar uma série de modelos estatísticos de múltiplas culturas em grade global (GGCM), identificou-se que os efeitos mais deletérios ocorrerão devido ao aumento de temperaturas em regiões de baixas latitudes. Este mesmo efeito também pode ser observado em dados de rendimento da safra agrícola de diversas regiões do globo avaliados por Challinor et al.» 
(2014). Em relação às pragas no campo, Jacques et al. (2019) afirmam que o aumento da temperatura atmosférica promovido pelas mudanças climáticas afeta a taxa de desenvolvimento e o voltinismo da lagarta Mythimma sequax, de acordo com a avaliação de modelos climáticos para o sul do Brasil.

Reduções no número de municípios catarinenses aptos para a produção, e alterações no período de cultivo e na época de semeadura, de acordo com o zoneamento climático para os próximos anos, já foram apontadas para a cultura da maçã (MASSIGNAM \& PANDOLFO, 2016), do milho (MASSIGNAM et al., 2015), banana (PANDOLFO et al., 2007), videira (PANDOLFO et al., 2008) e trigo (SANTI et al., 2017). Oliveira et al. (2018) afirmam que pode ocorrer um declínio de até $70 \%$ na produção leiteira do sul brasileiro, caso ocorra um aumento de $3^{\circ} \mathrm{C}$ na temperatura média global.

Além dos ecossistemas agrícolas, os ecossistemas naturais também passam por situações de estresse em que os organismos são submetidos a novas condições físicas, como as alterações da temperatura atmosférica e nos regimes de chuvas, que afetam a estabilidade dos ecossistemas (WEBSTER et al., 2017). Estas mudanças podem fazer com que o organismo desenvolva estratégias de adaptação, promovendo uma evolução da espécie. Considerando que a sobrevivência antrópica depende dos componentes vivos da natureza, as alterações em um espectro trarão consequências diretas para o outro espectro. Apesar de as mudanças cíclicas serem esperadas na dinâmica de espécies, estão ocorrendo redistribuições inesperadas e universais da vida na Terra. Isso afeta as relações-chave entre espécies que estão sendo rompidas por mudanças de habitat ou extinção de indivíduos, gerando novas comunidades bióticas (PECL et al., 2017). Estas novas comunidades podem afetar a atividade antrópica de forma benéfica ou maléfica

As populações nativas têm a capacidade de se ajustar a estas novas condições ambientais a partir de algumas respostas, que incluem a mudança geográfica para um local mais propício ao seu desenvolvimento, com uma reorganização ecológica, ou através de proces- sos de seleção natural dos indivíduos mais resistentes (WEBSTER et al., 2017), com mudanças na composição de uma comunidade e na competitividade dos indivíduos (BOULANGER et al., 2017). Porém esta não é a realidade para espécies vegetais nativas e endêmicas cujas comunidades são menores e, consequentemente, sofrem perdas de variabilidade genética à medida que os organismos vão se extinguindo devido à perda de hábitats. Isto vem causando uma redução gradual da biodiversidade de espécies vegetais nativas das florestas brasileiras (SILVA et al., 2019).

Outro malefício é a redistribuição de patógenos de plantas, que tendem a se deslocar para regiões mais quentes, como é o caso de bactérias fitopatogênicas do gênero Xanthomonas que têm atacado a cultura do tomate com maior frequência (BETTIOL et al., 2017). Em contrapartida, a modelagem indica a redução na incidência de outras doenças devido à redução de áreas com intensa umidade, como é o que vem ocorrendo com a sigatoka-negra da bananeira, causada pelo gênero de fungo Mycosphaerella (GHINI et al., 2007). As questões benéficas podem também estar relacionadas à implementação de novos cultivos resistentes, como o uso de sementes crioulas que, por serem fruto da seleção feita de acordo com sua qualidade e resistência ao longo dos anos, possuem maior capacidade de adaptarse às variações naturais em seu ambiente (NODARI \& GUERRA, 2015).

A Figura 2 é uma síntese dos principais problemas apresentados pelos ecossistemas agrícolas e naturais abordados neste texto.

\section{Estratégias de mitigação e adaptação}

As estratégias de adaptação são aquelas que ajudam o ecossistema a modificar-se de acordo com as mudanças no ambiente, e podem envolver características de resistência, resiliência ou de resposta das espécies. As estratégias de mitigação podem ser interpretadas de duas formas: como as ações que permitem que o ecossistema reduza a influência antropogênica sobre o clima global, ou as ações que reduzem o impacto das mudanças climáticas sobre as espécies (MILLAR et al., 2007). Pode-se citar ainda a adaptação evolucionária, quando a espécie interpreta a mudança climática como uma oportunidade para modificar seu sistema (HOFFMANN \& SGRÒ, 2011).

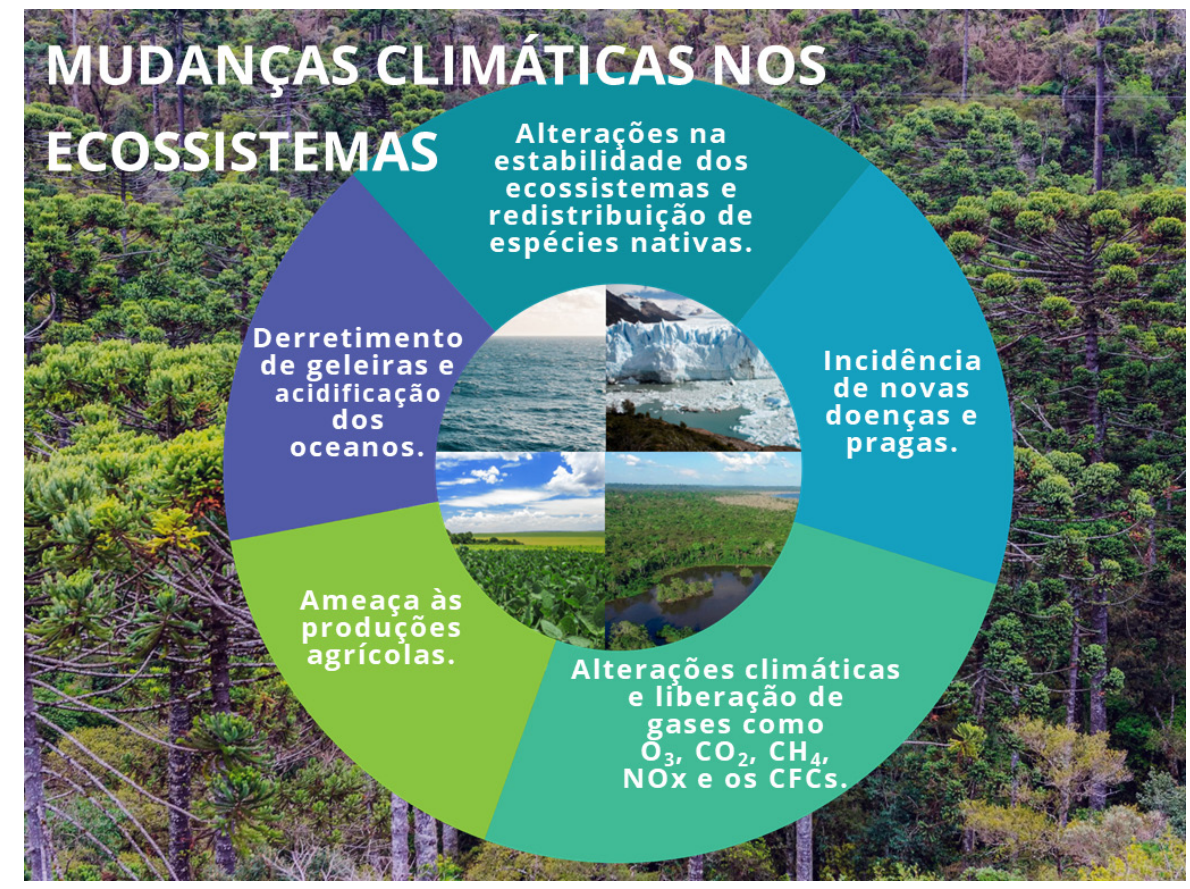

Figura 2. Mudanças Climáticas nos ecossistemas e seus principais impactos relacionados Fonte: Os autores (2019)

Figure 2. Ecosystem climatic changes and its major impacts. Source: Authors (2019) 
Levando em consideração as diferentes formas de adaptação, é importante que diferentes estratégias sejam aplicadas, de forma a garantir que o ecossistema, agrícola ou natural, sobreviva às mudanças de longo prazo (MILLAR et al., 2007). Aliam-se estudos que avaliam a vulnerabilidade e a forma que esta influenciará em um ecossistema, para que se tenha uma base de informações que serão utilizadas para desenvolver as estratégias de redução e mitigação de riscos (MARTINS et al., 2010). A adaptação às mudanças climáticas só será eficiente a partir do momento em que as respostas das espécies de cada local - principalmente as mais sensíveis, as espécieschave e as endêmicas - forem incluídas nos processos de tomada de decisão (PECL et al., 2017). Prevendo de que forma elas irão responder às mudanças no seu ambiente, torna-se possível definir os locais para onde irá ocorrer a migração das espécies, e assim promover atributos que garantam a adaptação a estes lugares (WEBSTER et al., 2017).

A identificação de espécies capazes de suportar as situações extremas de escassez hídrica e temperaturas altas, além da alta salinidade e da exposição à radiação ultravioleta, também pode ser aproveitada para o desenvolvimento genético de espécies agrícolas resistentes (HOFFMANN \& SGRÒ, 2011). Xu et al. (2018) afirmam que a modulação dos níveis de micro RNAs vegetais, que são reguladores da expressão dos genes envolvidos nas adaptações da planta às mudanças no ambiente, permite que sejam desenvolvidas culturas mais resistentes às mudanças climáticas. $\mathrm{A}$ hibridização natural entre espécies, apesar de ser considerada um efeito negativo para a conservação, pode também facilitar o processo de adaptação evolucionária, através da introdução de genes resistentes a espécies que anteriormente não possuíam a capacidade de sobreviver em ambientes extremos (HOFFMANN \& SGRÒ, 2011).

Reis Neto \& Araújo (2018) citam o instrumento denominado Redução do Desmatamento e da Degradação Florestal (REDD), para incentivar a redução de atividades que contribuem para o efeito estufa e aumentar a proteção das florestas nativas no Brasil. Este é um instrumento que vem sendo utilizado internacionalmente, mas para sua aplicação no Brasil são necessárias adaptações às caraterísticas dos remanescentes florestais e à realidade socioambiental de cada estado.

Coltri et al. (2019), avaliando formas de adaptar a cultura de café do sul do Brasil às mudanças climáticas, afirmam que é importante planejar o esquema de sombreamento da produção como forma de reduzir a temperatura na lavoura, a incidência de ventos e radiação, e aumentar a umidade do ar.

Abordando a relação entre ecossistemas naturais e a atividade agrícola, é importante considerar que, além de encontrar formas de adaptar as culturas a eventos extremos, também são necessárias adaptações na agricultura que reduzam a geração de gases poluentes e que visem aumentar o sequestro de carbono atmosférico pelas culturas. Challinor et al. (2014) apontam que mudanças para variedades mais resistentes, na época de plantio e no tempo de irrigação, podem garantir um aumento no rendimento da safra em $7-15 \%$, principalmente nas culturas de grãos. Neste âmbito, os modelos de simulação de culturas têm sido utilizados com êxito.

Os modelos de simulação de culturas são um exemplo de tecnologia que permite avaliar os riscos na produção agrícola. Eles indicam de que forma a cultura irá crescer e se desenvolver, de acordo com dados históricos do manejo desta cultura e das variações nas condições climáticas no local, indicando a melhor época de plantio (CHALLINOR et al., 2018).

Com relação ao papel do setor agrícola em realizar o sequestro de carbono atmosférico, Tao et al. (2019) afirmam que a intensificação da agricultura orgânica seria importante, devido a um aumento da produção através do uso de fertilizantes naturais e de um manejo eficiente dos resíduos vegetais, associados à prática do plantio direto. Estes métodos reduzem o impacto sofrido pelo solo e aumentam sua capacidade de absorver carbono atmosférico através da vegetação, fazendo ainda com que ele mantenha seus níveis de fertilidade e contribua para o bom rendimento da cultura, sendo esta uma forma de mitigação dos impactos já existentes.
Outra estratégia relacionada ao sequestro de carbono envolve a aplicação dos sistemas de diversificação da produção como a integração lavoura-pecuária-floresta (ILPF) e integração pecuáriafloresta (IPF) (ANGELOTTI et al. 2015). Estes métodos, além de aumentarem o estoque de carbono do solo, permitem a recuperação de áreas degradadas, promovem um aumento da diversidade biológica e atuam na mitigação de processos de degradação do ambiente, como a desertificação pelo uso de monoculturas.

Tendo em vista, ainda, que os ecossistemas naturais afetam a sociedade de forma direta, Scarano (2017) chama atenção para a necessidade de combinar a justiça social, a saúde do meio ambiente e a produtividade econômica como estratégias para reduzir os riscos aos quais um ecossistema pode ser exposto, adaptando estas estratégias de acordo com a realidade de cada região, na busca por um desenvolvimento sustentável. O autor chama esta política pública de "Adaptação com base nos ecossistemas" e afirma que ela seria ideal para garantir a sobrevivência do ecossistema natural e a adaptação da sociedade às mudanças climáticas.

Esta adaptação ocorreria através do uso dos serviços ecossistêmicos, relacionando estes a políticas socioeconômicas e de desenvolvimento, com vistas à redução dos níveis de gás carbônico antrópico liberado. $\mathrm{O}$ autor propõe também o pagamento por serviços ecossistêmicos e o ecoturismo em áreas protegidas como partes importantes da política, além da interdisciplinaridade das ciências envolvidas, nas áreas de meio ambiente, social e econômica. Esta seria a estratégia mais realista quando se fala a respeito da relação entre os ecossistemas naturais e a atividade antrópica. Ela já tem sido uma preocupação das políticas públicas brasileiras que visam integrar o agronegócio com as necessidades socioambientais (SAMBUICHI et al., 2014). Foguesatto et al. (2019) afirmam que, antes de aplicar as políticas públicas para incentivar a aplicação de práticas de agricultura sustentável no Brasil, é importante entender a percepção dos agricultores quanto à questão ambiental. 


\section{Considerações finais}

De forma geral, as mudanças climáticas e seus impactos são crescentes, e a atenção social às estratégias de mitigação e adaptação é importante para garantir a sobrevivência aos impactos. Como o setor agrícola depende diretamente da forma como o meio ambiente responde às mudanças climáticas, uma maneira de garantir a sobrevivência dos sistemas produtivos é compreender as formas de evitar que o ambiente sofra o efeito das mudanças climáticas. Não se pode negar, porém, o importante papel que o setor agrícola tem sobre a intensificação das mudanças climáticas, principalmente quando se aborda o efeito estufa. A geração de gases e partículas poluentes e o aumento da concentração destas substâncias na atmosfera contribuem para o aumento nas médias de temperatura.

Porém, a divulgação a respeito destas formas de mitigação e adaptação aos impactos ainda é falha, e muitas delas permanecem muito restritas à comunidade científica. É necessário que esta questão seja trabalhada, buscando formas de atrair o interesse da sociedade e dos produtores agrícolas em testar as estratégias propostas. Para isso, é importante que se tenha uma colaboração maior dos meios de comunicação, agindo em parceria com os cientistas e divulgando os impactos das mudanças climáticas e os resultados promissores de pesquisas com uma linguagem popular e de fácil compreensão. Além disso, também é necessária a ação do governo, no incentivo à adoção das práticas propostas, e na contínua aplicação dos instrumentos legais de comando e controle.

\section{Referências}

ANGELOTTI, F.; SIGNOR, D.; GIONGO, V. Mudanças climáticas no semiárido brasileiro: experiências e oportunidades para o desenvolvimento. Revista Brasileira de Geografia Física, v. 8, número especial IV SMUD, p. 484-495, 2015.

EMBRAPA. Aquecimento Global e a nova geografia da produção agrícola no Brasil. São Paulo: Clima e Agricultura, 84p.,2008.
BARRY, R. C. Atmosfera, tempo e clima. Tradução: COSTA, R. C. Dados eletrônicos, Bookman: Porto Alegre, 2013.

BETTIOL, W.; HAMADA, E.; ANGELOTTI, F.; AUAD, A. M.; GHINI, R. Aquecimento global e problemas fitossanitários. Brasília, DF: Embrapa, 2017, 488 p.

BOULANGER, Y.; TAYLOR, A. R.; PRICE, D. T.; CYR, D.; MCGARRIGLE, E.; RAMMER, W.; SAINTE-MARIE, G.; BEAUDOIN, A.; GUINDON, L.; MANSUY, N. Climate change impacts on forest landscapes along the Canadian southern boreal forest transition zone. Landscape Ecology, v. 32, p. 1415-1431, 2017. DOI: dx.doi.org/10.1007/s10980-0160421-7. Acesso em: 27 fev. 2020.

CAI, W.; BORLACE, S.; LENGAIGNE, M.; RENSCH, P.; COLLINS, M.; VECCHI, G.; TIMMERMANN, A.; SANTOSO, A.; MCPHADEN, M. J.; WU, L.; ENGLAND, M. H.; WANG, G.; GUILYARDI, E.; JIN, F. Increasing frequency of extreme El Niño events due to greenhouse warming. Nature: Climate Change, v. 4, Fev./2014. DOI: dx.doi.org/10.1038/nclimate2100. Acesso em: 27 fev. 2020.

CHALLINOR, A. J.; WATSON, J.; LOBELL, D. B.; HOWDEN, S. M. SMITH, D. R.; CHHETRI, N. A meta-analysis of crop yield under climate change and adaptation. Nature Climate Change, v. 4, abr./2014. DOI: dx.doi. org/10.1038/NCLIMATE2153. Acesso em: 27 fev. 2020.

CHALLINOR, A. J.; MULLER, C.; ASSENG, S.; DEVA, C.; NICKLIN, J.; WALLACH, D.; VANUYTRECHT, E.; WHITFIELD, S.; RAMIREZ-VILLEGAS, J.; KOEHLER, A. Improving the use of crop models for risk assessment and climate change adaptation. Agricultural Systems, v. 159, p. 296-306, 2018. DOI: dx.doi. org/10.1016/j.agsy.2017.07.010. Acesso em: 27 fev. 2020.

COLTRI, P. P..; PINTO, H. S.; GOLÇALVES, R. R. V.; ZULLO JUNIOR, J.; DUBREAUIL, V. Low levels of shade and climate change adaptation of Arabica coffee in southeastern Brazil. Heliyon. V.5, e.01263, 2019. DOI: dx.doi.org/10.1016/j.heliyon.2019. e01263. Acesso em: 27 fev. 2020.

DAMATTA, F. M.; RAHN, E.; LADERACH, P.; GHINI, R.; RAMALHO, J. C. Why could the cof- fee crop endure climate change and global warming to a greater extent than previously estimated? Climatic Change. v.152, p.167178, 2019. DOI: dx.doi.org/10.1007/s10584018-2346-4. Acesso em: 27 fev. 2020.

DUBREUIL, V.; FANTE, K. P.; PLANCHON, O.; SANT'ANNA NETO, J. L. Climate change evidence in Brazil from Köppen's climate annual types frequency. International Journal of Climatology. v.39, p.1446-1456, 2019. DOI: dx.doi.org/10.1002/joc.5893. Acesso em: 27 fev. 2020

FOGUESATTO, C. R.; BORGES, J. A. R.; MACHADO, J. A. D. Farmers' typologies regarding environmental values and climate change: Evidence from southern Brazil. Journal of Cleaner Production. v.232, p.400-407, 2019. DOI: dx.doi.org/10.1016/j. jclepro.2019.05.275. Acesso em: $27 \mathrm{fev}$. 2020.

GHINI, R.; HAMADA, E.; GONÇALVES, R.V.; GASPAROTTO, L.; PEREIRA, J.C.R. Análise de Risco das Mudanças Climáticas Globais sobre a Sigatoka-negra da Bananeira no Brasil. Fitopatologia Brasileira, v.32, n.3, p. 197204, mai-jun, 2007.

GHINI, R.; HAMADA, E.; BETTIOL, W. Impactos das mudanças climáticas sobre doenças de importantes culturas no Brasil. Jaguariúna, Embrapa Meio Ambiente, 2011. 356 p.

HOFFMANN, A. A.; SGRÒ, C. M. Climate change and evolutionary adaptation. Nature, v. 470 , p. $479-485$, fev./2011. DOI: dx.doi.org/10.1038/nature09670. Acesso em: 27 fev. 2020.

ICLEI - Governos Locais pela Sustentabilidade. Análise das emissões de GEE no Brasil (1970-2013) e suas implicações para políticas públicas. São Paulo: Observatório do Clima, 52 p., 2015. Disponível em: https:// s3-sa-east-1.amazonaws.com/seeg.tracersoft.com.br/wp-content/uploads/2015/08/ sintese_2015.pdf Acesso em: 29 out. 2019.

IPCC . Summary for Policymakers. In: Climate Change 2013: The Physical Science Basis. Contribution of Working Group I to the Fifth Assessment Report of the Intergovernmental Panel on Climate Change. Cambridge University Press, Cambridge, United Kingdom and New York, USA, 2013. 
IPCC. Summary for Policymakers. In: MASSON-DELMOTTE, V., P. ZHAI, H.-O. PÖRTNER, D. ROBERTS, J. SKEA, P.R. SHUKLA, A. PIRANI, W. MOUFOUMA-OKIA, C. PÉAN, R. PIDCOCK, S. CONNORS, J.B.R. (eds.). Global Warming of $1.5^{\circ} \mathrm{C}$ : An IPCC Special Report on the impacts of global warming of $1.5^{\circ} \mathrm{C}$ above preindustrial levels and related global greenhouse gas emission pathways, in the context of strengthening the global response to the threat of climate change, sustainable development, and efforts to eradicate poverty. 2018. 32p. Disponível em: https://www.ipcc. ch/sr15/. Acesso em: 27 fev. 2020.

JACQUES, J.; SAMPAIO, F.; SANTOS, H. T.; MARCHIORO, C. A. Climate change and voltinism of Mythimna sequax: the location and choice of phenological models matter. Agricultural and Forest Entomology. v.21, p. 431-444, 2019. DOI: dx.doi.org/10.1111/ afe.12350. Acesso em: 27 fev. 2020.

MARTINS, S. R.; SCHLINDWEIN, S. L.; D'AGOSTINI, L. R.; BONATTI, M.; VASCONCELOS, A. C. F.; HOFFMANN, A. F. FANTINI, A. C. Mudanças climáticas e vulnerabilidade na agricultura: desafios para desenvolvimento de estratégias de mitigação e adaptação. Revista Brasileira de Ciências Ambientais, n. 17 , Set./2010.

MASSIGNAM, A. M.; PANDOLFO, C. Já podemos observar os impactos das mudanças climáticas na cultura da maçã em Santa Catarina? Agropecuária Catarinense. Florianópolis - SC, v.29, n.3, 2016.

MASSIGNAM, A. M.; PANDOLFO, C.; RICCE, W. S.; SANTI, A.; MACHADO, L. N. Impacto das mudanças climáticas para o período futuro 2071-2100 no zoneamento do miIho no Sul do Brasil. Agropecuária Catarinense. Florianópolis - SC, v.28, n.2, p.55-60, ago.2015/dez.2015.

MILLAR, C.; STEPHENSON, N. L.; STEPHENS, S. L. Climate change and forests of the future: managing in the face of uncertainty. Ecological Applications, v. 17, n.8, p. 2145-2151, 2007.

NODARI, R. O.; GUERRA, M. P. A agroecologia: estratégias de pesquisa e valores. Estudos Avançados, v. 29, n. 83, p. 183 207, 2015. DOI: dx.doi.org/10.1590/s0103-
40142015000100010. Acesso em: 27 fev. 2020.

OLIVEIRA, Z. B.; SOUZA, I. J.; LINK, T. T.; BOTTEGA, E. L.; Cenários de mudanças climáticas e seus impactos na produção leiteira no sul do brasil. Brazilian Journal of Biosystems Engineering. v. 12, n.2, p.110-121, 2018.

PANDOLFO, C.; HAMMES, L. A.; CAMARGO, C.; MASSIGNAM, A. M.; PINTO, E. S. P.; LIMA, M. Estimativas dos impactos das mudanças climáticas nos zoneamentos da cultura da banana e da maçã no Estado de Santa Catarina. Agropecuária Catarinense. Florianópolis - SC, v.20, n.2, jul. 2007.

PANDOLFO, A.; MASSIGNAM, A. M.; SILVA, A L.; HAMMES, L. A.; BRIGHENTI, E.; BONIN, V. Impacto das mudanças climáticas nas horas de frio, graus-dias e amplitude térmica do ar para a videira (Vitis vinifera L.) Var. Cabernet sauvignon, no Estado de Santa Catarina. Revista Brasileira de Agrometeorologia, v.16, n. 3, p.267-274, dezembro/2008.

PECL, G. T.; ARAÚJO, M. B.; BELL, J. D.; BLANCHARD, J.; BONEBRAKE, T. C.; CHEN, I. C.; CLARK, T. D.; COLWELL, R. K.; DANIELSEN, EVENGÅRD, F. B.; FALCONI, L.; et al. Biodiversity redistribution under climate change: Impacts on ecosystems and human well-being. Science, v. 355, p. 1389 - 1398, mar. /2017. DOI: dx.doi.org/10.1126/science.aai9214. Acesso em: 27 fev. 2020.

REIS NETO, A. F.; ARAÚJO, M. S. B. Direito e mudanças climáticas: Florestas nativas em Pernambuco. Revista Direito Ambiental e sociedade. v. 8 , n. 3, set./dez. p. 167-193, 2018.

ROSENZWEIG, C.; ELLIOTT, J.; DERYNG, D.; RUANE, A. C.; MÜlleR, C.; ARNETH. A.; BOOTE, K. J.; FOLBERTH, H.; GLOTTERI, M.; KHABAROV, N.; NEUMANN, K.; et al. Assessing agricultural risks of climate change in the 21st century in a global gridded crop model intercomparison. PNAS, v. 111, n. 9, p. 3268-3273, 2014. DOI: dx.doi.org/10.1073/ pnas.1222463110. Acesso em: 27 fev. 2020.

SAMBUICHI, R. H. R., SILVA, A. P. M., OLIVEIRA, M. A. C., SAVIAN, M. Políticas agroambientais e sustentabilidade: desafios, oportunidades e lições aprendidas. IPEA, Brasília. 2014
SANTI, A.; VICARI, M. B.; PANDOLFO, C.; DALMAGO, G. A.; MASSIGNAM, A. M.; PASINATO, A. Impacto de cenários futuros de clima no zoneamento agroclimático do trigo na região Sul do Brasil. Agrometeoros. Passo Fundo - RS, v.25, n.2, p.303-311, dez 2017.

SCARANO, F. R. Ecosystem-based adaptation to climate change: concept, scalability and a role for conservation science. Perspectives in Ecology and Conservation, v. 15, p. 65-73, 2017. DOI: dx.doi.org/10.1016/j. pecon.2017.05.003. Acesso em: $27 \mathrm{fev}$. 2020.

SILVA, J. M. C.; RAPINI, A.; BARBOSA, L. C. F.; TORRES, R. R. Extinction risk of narrowly distributed species of seed plants in Brazil due to habitat loss and climate change. PeerJ. v.7, e. 7333, 2019. DOI: dx.doi.org/10.7717/ peerj.7333. Acesso em: 27 fev. 2020.

TAO, F.; PALOSUO, T.; VALKAMA, E.; MAKIP$A A, R$. Cropland soils in China have a large potential for carbon sequestration based on literature survey. Soil \& Tillage Research, v. 186, p. 70-78, 2019. DOI: dx.doi. org/10.1016/j.still.2018.10.009. Acesso em: 27 fev. 2020.

TAVARES, P. S.; GIAROLLA, A.; CHOU, S. C.; SILVA, A. J. P.; LYRA, A. A. Climate change impact on the potential yield of Arabica coffee in southeast Brazil. Regional Environmental Change. v.18, p.873-883, 2018. DOI: dx.doi. org/10.1007/s10113-017-1236-z. Acesso em: 27 fev. 2020.

WEBSTER, M. S.; COLTON, M. A.; DARLING, E. S.; ARMSTRONG, J.; PINSKY, M. L.; KNOWLTON, N.; SCHINDLER, D. E. Who Should Pick the Winners of Climate Change? Trends in Ecology \& Evolution, v. 32, n. 3, 2017. Disponível em: dx.doi.org/10.1016/j. tree.2016.12.007. Acesso em: 27 fev. 2020.

XU, J.; HOU, Q.; KHARE, T.; VERMA, S. K.; KUMAR, V. Exploring miRNAs for developing climate-resilient crops: A perspective review. Science of the Total Environment, v. 653, p. 91-104, 2018. DOI: dx.doi.org/10.1016/j. scitotenv.2018.10.340. Acesso em: $27 \mathrm{fev}$. 2020 . 